\title{
INTRALAMINAR CRACK GROWTH RATES OF INTERACTING CRACKS RELATED TO INDIVIDUAL ENERGY RELEASE RATES
}

\author{
J.J. Bender ${ }^{1}$, B.L.V. Bak ${ }^{1 *}$, L. Carreras ${ }^{1}$ and E. Lindgaard ${ }^{1}$ \\ ${ }^{1}$ The CraCS research group, Aalborg University, Fibigerstraede 16, DK-9220 Aalborg East, Denmark \\ *brianbak@mp.aau.dk
}

The crack growth rate is related to the energy release rate through a Paris law-like relation. This relation is typically based on a single interlaminar crack in e.g. a DCB specimen. Paris like curves have also been generated for intralaminar cracks in the literature [1] considering isolated cracks, where the energy release rate is based on the general stress level in the plies.

In this work, results from an experimental campaign [2] are analyzed in an FE framework. The experimental campaign is carried out with GFRP specimens with a $\left[ \pm 45,0_{5}\right]_{S}$ lay-up in load controlled tension-tension constant and variable amplitude fatigue. With the developed parametric FE model it is possible to automatically create an FE mesh to represent any distribution of cracks in multiple layers. The only input is the coordinates of the crack tips, and which layer they belong to. A structured mesh with brick elements is used around each crack which spans from $0.25 \mathrm{~mm}$ to $>10 \mathrm{~mm}$ in length. All the cracks detected through experiments are modelled in the FE model to accurately represent the stress distribution in the laminate caused by up to 1000 cracks per layer. The crack growth rate of each of the intralaminar crack tips (determined in the experiments as in Figure $1 \mathrm{a}-\mathrm{c}$ ) are related to the energy release rate at the individual crack tips (determined in the FE model as in Figure $1 \mathrm{~d}$-e). The energy release rates are determined based on the Virtual Crack Closure Technique.

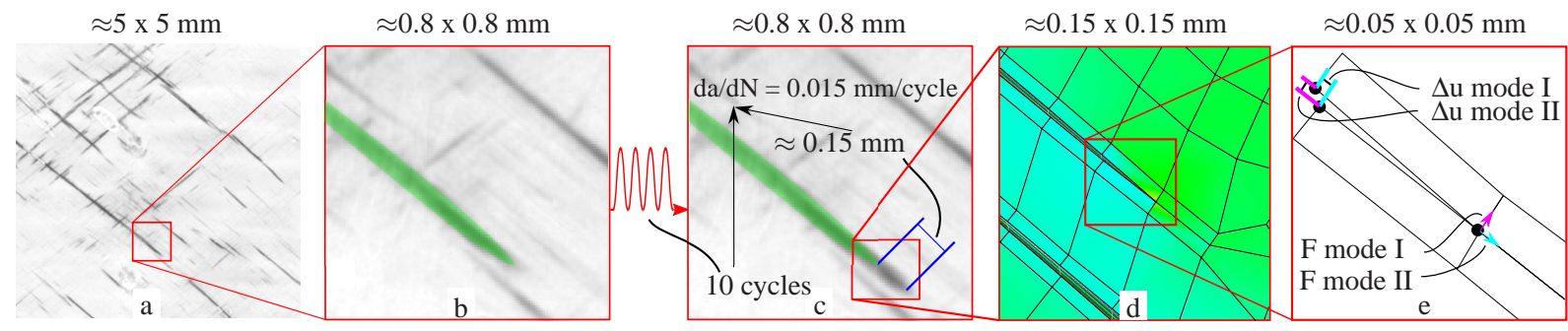

Figure 1. Crack propagation early in test, and energy release rate in FEM based on VCCT. This work provides insight into the effect of variable amplitude loading on the crack growth rates of crack tips in regions with reduced stresses due to shielding from multiple cracks. Detailed studies with emphasis on variable amplitude loading are presented at ECCOMAS. The studies focus on the effect of shielding from multiple cracks, and cracks in adjacent layers on the relation between crack growth rates and energy release rates.

\section{References}

[1] J. A. Glud, J. M. Dulieu-Barton, O. T. Thomsen, L. C. T. Overgaard (2017) Fatigue damage evolution in GFRP laminates with constrained off-axis plies. Composites: Part A, 95, 359-369.

[2] J. J. Bender, B. L. V. Bak, S. M. Jensen, and E. Lindgaard (2021) Effect of Variable Amplitude Block Loading on Intralaminar Crack Initiation and Propagation in Multidirectional GFRP Laminate. Submitted. 